\title{
Simulative Analysis and experimental Investigation of Common Rail Injection Pumps lubricated with tailor-made Biofuels
}

\author{
S. Heitzig, S. Drumm and H. Murrenhoff \\ Institute for Fluid Power Drives and Controls (IFAS), RWTH Aachen University, Aachen, Germany \\ E-mail: Stefan.Heitzig@ifas.rwth-aachen.de, \\ Hubertus.Murrenhoff@ifas.rwth-aachen.de
}

\begin{abstract}
In the scope of the cluster of excellence "Tailor-Made Fuels from Biomass" new biofuels are developed within an interdisciplinary research approach at RWTH Aachen University. The most promising fuel candidates so far tend to have a low viscosity and a low lubricity compared to diesel fuel. It is the task of the authors to develop a guideline for designing injection systems that are especially adapted to these fuels. The main focus is on high pressure pump within common rail systems. In this paper, the effects of those fuel candidates on the tribological contacts in standard common rail pumps are investigated by means of experiments and simulations. On the experimental side a test rig is presented, which allows the measurement of the transversal force on a piston and the friction force, which occur in the piston/bushingcontact. On the simulation side, elastohydrodynamic simulation models of several tribological contacts within the standard pump are presented. Results of simulation and measurement are presented.
\end{abstract}

Keywords: Elastohydrodynamic simulation, friction forces, tribological contacts, common rail pump, fuels, journal bearings

\section{Introduction and Motivation}

\subsection{Tailor-made Fuels from Biomass}

Environmental pollution and the exploitation of nonrenewable resources of modern times force the development of new sustainable biofuels. One approach to find such biofuels is pursued within the cluster of excellence "TailorMade Fuels from Biomass" at RWTH Aachen University. Within the cluster, new biofuels are developed and tested in an interdisciplinary approach, see fig. 1.

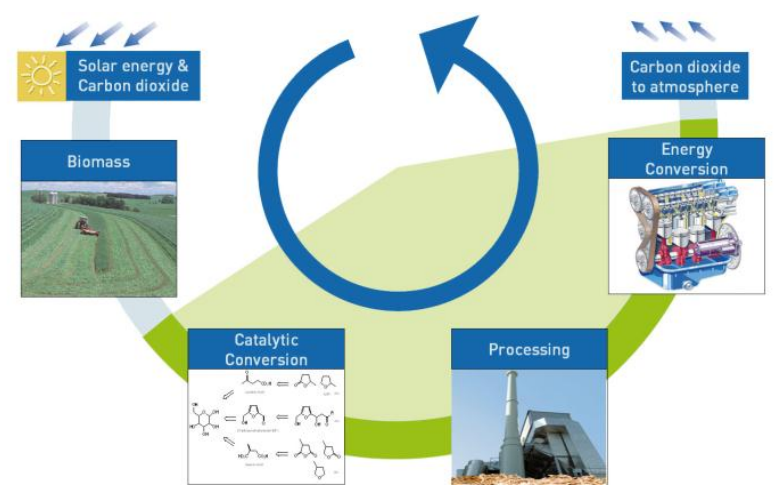

Figure 1: Tailor-made Fuels from Biomass

The fluids are evaluated regarding their suitability for use as a biofuel on the basis of their conversion, combustion and tribological characteristic. A lot of the investigated fuels have an excellent combustion and canversion characteristic but poor tribological properties. They can differ severely from conventional fuels in their lubrication and viscosity characteristics. Therefore, tribological problems and higher efforts to pressurise the fuel to the injection pressure level have to be expected in fuel-lubricated common rail pumps when operated with the new fuel candidates. In order to facilitate a widespread usage of potential new biofuels, research at the Institute for Fluid Power Drives and Controls (IFAS) focuses on two approaches to ensure a proper functioning of the tribological systems. On the one hand, low-lubricity biofuels can be blended with highlubricity biofuels in order to enhance their lubrication characteristics in the boundary lubrication regime [1,2]. On the other hand, research on the components reveals what extent modifications of those components (micro and macro geometry, materials, coatings, etc.) can contribute reducing the effort that is necessary in order to pressurise the fuel candidates.

\subsection{Common Rail Injection Pump}

Diesel injection systems of modern passenger cars are nowadays generally designed as so-called common rail systems. In those systems the pressure build-up is decoupled from the injection process by means of the so-called rail, which functions as a hydraulic accumulator. In this paper the focus is on the common rail pump, which is used to pressurise the fuel to the injection pressure level. From the 
hydraulic point of view this is a challenging task for several reasons. Firstly, the pressure level of common rail systems is much higher than in standard hydraulic applications. Systems of the first generation started with a maximum pressure level of $1350 \mathrm{bar}$. In the second and third generation the maximum pressure level was increased in order to achieve a more efficient combustion and fewer emissions. To fulfill the upcoming regulation regarding future emission limits, the next generation of common rail systems will operate at even higher pressures from 2500 up to 3000 bar. Secondly, from a tribological point of view the fluid properties of diesel are worse in comparison to standard hydraulic fluid. According to DIN EN 590, at $40{ }^{\circ} \mathrm{C}$ diesel has a viscosity within the range from 2,0 up to $4,5 \mathrm{~mm}^{2} / \mathrm{s}$. This leads to more leakage losses in pumps and more operation of the tribological contacts in the mixed and boundary lubrication regime. And thirdly, those pumps are for the rather cost sensitive automotive sector.
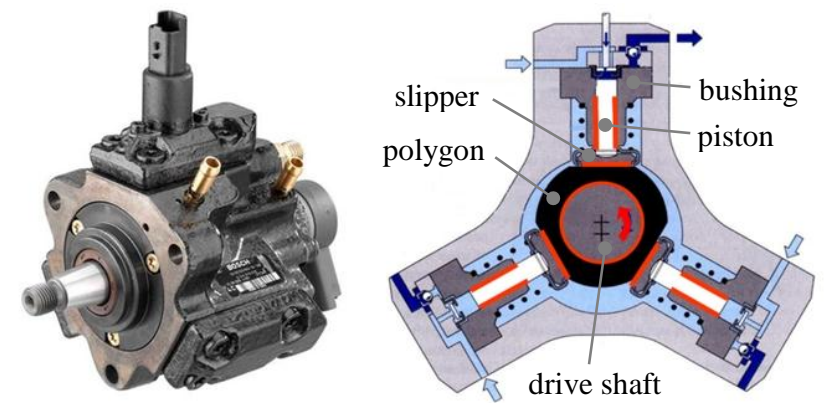

Figure 2: Common rail pump CP1. Source: Robert Bosch $\mathrm{GmbH}$

As a starting point the effects of the fuel candidates on a standard common rail pump of the first generation are studied in this paper. This kind of pump, a BOSCH CP1 [3], is a radial piston type design and consist of three pistons, see fig. 2. Via a metal sheet clamp, each piston is connected to a piston slipper, which is sliding on a planar surface of the polygon ring. This ring is connected via a rotational journal bearing to the eccentric shoulder of the pump drive shaft. All tribological contacts in this pump are lubricated by the fuel itself.

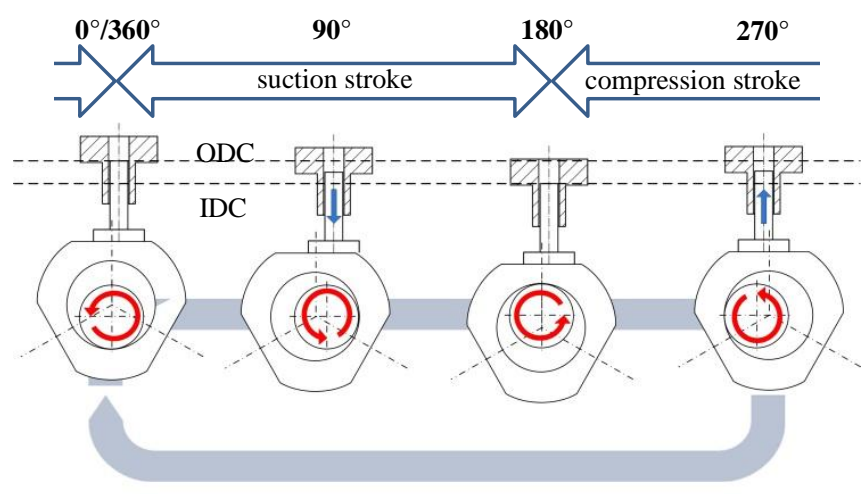

Figure 3: Sequence of one revolution

In fig. 3 the kinematics of this kind of pump are illustrated for the movement of one piston unit. The revolution starts at $0^{\circ}$ drive shaft angel with the transition from the compression stroke to the suction stroke. The piston is at the outer dead center (ODC) and hence its velocity is zero. From $0^{\circ}$ to $180^{\circ}$ the suction stroke is continuous and the piston moves downwards. At $90^{\circ}$ the direction of the relative motion in the sliding contact between slipper and polygon changes its direction. At $180^{\circ}$ the piston is at the inner dead center (IDC) of its movement. From $180^{\circ}$ to $360^{\circ}$ the compression stroke is continuous and the piston moves upwards again.

At closer inspection of cross section of the pump in fig. 2 it becomes obvious that there is a slight displacement $d$ between the axis of each piston and the axis of the drive shaft. This detail in design, which can be found in every common rail pump of this type, is exemplified in fig. 4 .

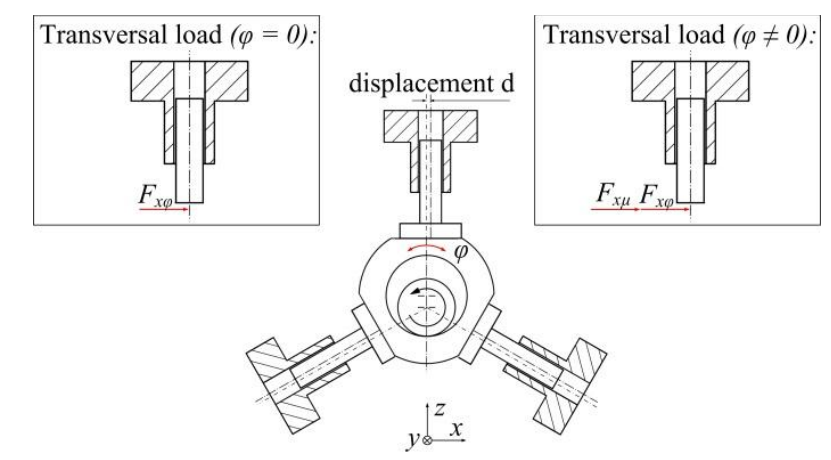

Figure 4: Tilting of the polygon ring

The motivation for this displacement $d$ is a reduction of the tilting $\varphi$ of the polygon ring. This tilting is determined by the forces acting on the polygon ring. In the investigated pump type each piston axis has a displacement $d$ to the drive axis of half the eccentricity $e$ of the drive shaft. With this displacement the tilting of the polygon ring is reduced and hence the transversal load $F_{x}$ on each piston, see eq. 1 .

$$
F_{x}=F_{x \varphi}+F_{x \mu}=F_{z} \cdot \tan (\varphi)+F_{\mu} \cdot \cos (\varphi)
$$

If no tilting occurs $(\varphi=0)$, the transversal load $F_{x}$ is equal to the friction force $\mathrm{F}_{\mu}$ in the polygon/slipper-contact, because the bearing surface on the polygon is orthogonal to the axis of the piston. As soon as the polygon is tilted $(\varphi \neq 0)$, a transversal force $\mathrm{F}_{x \varphi}$ due to the inclined plane has to be taken into account.

\subsection{Focus of this Paper}

Within the scope of this paper simulative and experimental approaches investigating the effects of the new fuel candidates on standard common rail pumps are discussed. The presented experimental approach tries to cover the operating characteristic and conditions of standard pumps as realistic as possible. But nevertheless, a few differences occur between the operating characteristic and conditions in the test rig and in a standard pump. This experimental approach allows the measurement of the friction force in the piston/bushing-contact as well as the transversal load on the piston. In the simulative approach further contacts are taken into consideration to reach a better comparability of measurement and simulation. As this paper will demonstrate, there are several specific reasons why a satisfying comparability of measurement and simulation is 
difficult to reach at this point. Improvements on the experimental side will be exposed, which will enable a better comparability in the future.

\section{Experimental Approach}

\subsection{Test Rig Set-Up}

Over the past decades several test rigs were designed to measure the friction forces in tribological contacts within hydraulic pumps [4] [5] [6] [7] [8]. The basic principle chosen for this test rig is comparable to the one developed by Breuer [9].

The design of the test rig is shown in fig. 5 (a). This design allows the measurement of the friction force (z-direction) and the transversal load (x-direction) of one piston unit. All tribologically relevant parts are taken from standard pumps (piston, bushing, piston slipper, polygon ring, drive shaft). One bushing is separated from the housing and connected to the force measurement platform. In order to compensate the huge forces occurring because of the pressure build-up in the piston chamber, a compensation piston with the same diameter is installed. This piston transmits the pressure forces directly to the base frame so that these forces are not measured by the force sensors.

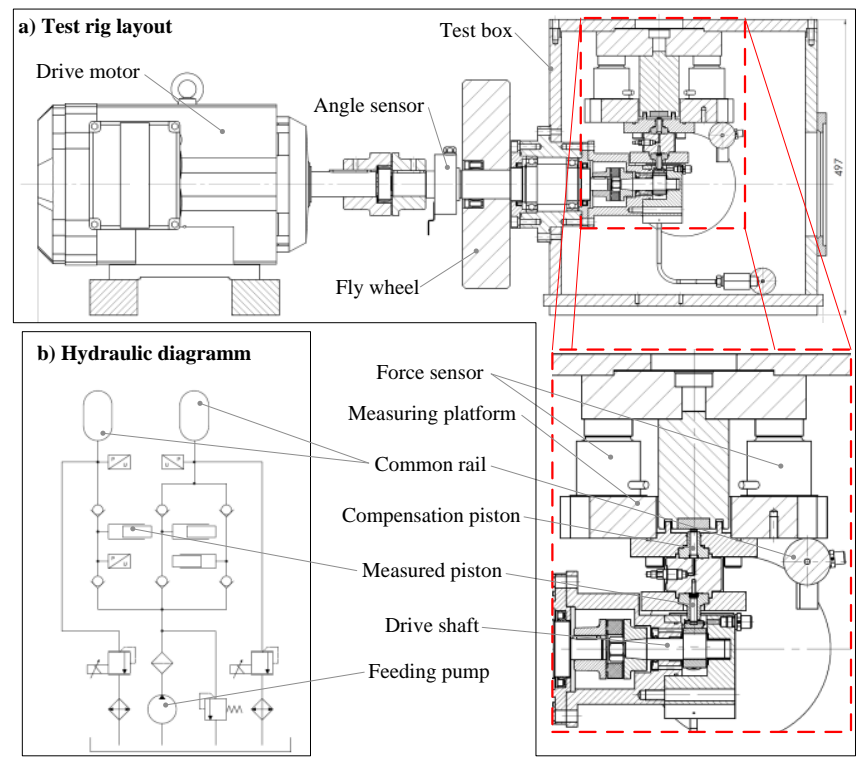

Figure 5: Test rig, layout (a) and hydraulic diagram (b)

Figure 5 (b) shows the hydraulic diagram of the rig. A simple external gear pump is used as a fuel feeding pump. To achieve a constant supply pressure of 6 bar a pressure relieve valve is installed. Two check valves at each piston are used for commutation. The flow of the pistons is pumped to two different common rails (accumulators). One rail is connected to the measured piston while the other rail is supplied by the unmodified pistons. The pressure in each common rail is controlled by a pressure relieve valve. By means of the use of two common rails it is achieved that only low pressure connections are installed between the platform measuring the force and the base frame of the test rig. That is how no additional forces develope because of pressure pulsation in the high pressure system are induced to the force measuring system.

A more detailed description of the test rig can be seen in [10].

\subsection{Comparison of Test Rig and Standard Pump}

Even though operating conditions of the tribological contacts in the test rig are similar to those in standard pumps, there are a few differences. In the following, these differences will be discussed.

In order to separate the pressure forces from the friction forces a compensation piston is added to the test rig. This will slow down the pressure build-up in the piston chamber, because additional leakage occurs at this piston/bushingcontact. In addition to that, friction forces will occur in this contact as well. Even if there is no relative motion between the surfaces in this contact, hydrodynamic friction forces due to the leakage will occur at the bushing and will be measured by the force sensors. In order to be able to install a dynamic pressure sensor and the compensation piston, dead volume is added to the piston chamber of the measured piston unit. Like the additional leakage due to the compensation this will slow down the pressure build-up as well.

For the reasons explained above, two separated common rails are used in the rig. Thus, the pressure level in the measured piston/bushing unit is completely decoupled from the pressure level in the other two piston units. The pressure levels in the two rails are adjusted by manually adjustable pressure relief valves. Slightly different pressure levels as well as different dynamic characteristics will occur in the two rails. Furthermore, in a standard pump the housing is pressurised (roughly $3-6$ bar) and flushed by the flow of the feeding pump. At this point this is not the case in the rig. In order to avoid a force shunt between the pump housing and the force measurement platform, no sealing is installed between the housing and the bushing. As a consequence it is not possible to pressurise the housing of the rig. The flushing of the housing in the rig is only achieved by the leakage of the three piston units and not by the total flow of the supply pump. A further difference between pump and test rig is that the fuel in the rig is pressurised several times. In a common rail system the pressurised fuel is burned after compression. Only a small amount is pressurised several times. In the rig an aging of the diesel can occur during the measurement, because it is pressurised and throttled several times.

Some of those differences will be eliminated in future measurements, see Chapter 5 of this paper.

\subsection{Measurement Results}

In a first step, measurement with standard diesel were conducted to prove the functioning of the rig and to detect weaknesses. Measurement results at a selected point of operation (rail pressure: $1800 \mathrm{bar}$; revolution: 200 1/min) are shown in fig. 6. 


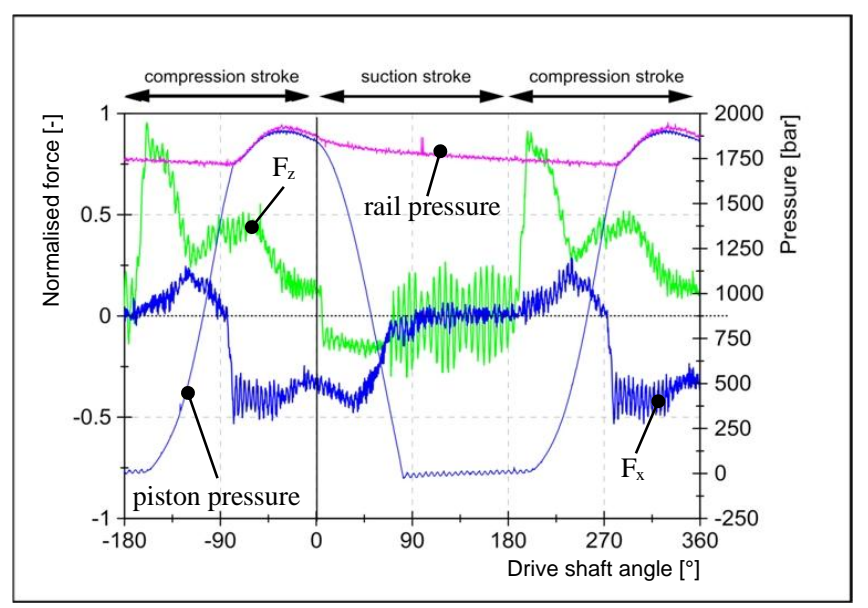

Figure 6: Measurement results

The revolution starts at the outer dead center of the piston with a rotation angle of $0^{\circ}$. From $0^{\circ}$ to $180^{\circ}$ the piston is moving downwards (suction stroke) and from $180^{\circ}$ to $360^{\circ}$ upwards (compression stroke). Forces during the suction stroke are on a low level due to the low level of the piston pressure of just a few bars. Just at the very beginning of the suction stroke there is still a higher piston pressure level and hence a higher level of forces. This higher level of piston pressure is due to the compressibility of the fuel and the elasticity of the components. At roughly $80^{\circ}$ the decompression is completed and the piston pressure stays on the pressure level of the feeding pump. As soon as the compression stroke is entered, the pressure in the piston chamber raises. Due to a great amount of leakage in the piston/bushing-contact of the measured piston unit and the compensating piston as well as due to the compressibility of the fuel and the elasticity of the solid bodies, the raise of the pressure takes some time. At roughly $270^{\circ}$ the piston pressure reaches the pressure level of the rail. From then on, fuel is delivered to the rail. A few degrees before the suction stroke is entered the pressure level in the piston chamber decreases. At this point the piston movement is not fast enough to compensate the leakage losses. The transversal forces on the piston $F_{x}$ are submitted to a change in direction at $270^{\circ}$, because at that point the relative motion in the polygon/slipper-contact changes. This is also the case at $90^{\circ}$, but at that point the change of direction is not visible in the plots due to the low level of the force.

As exemplified before, the transversal load on the piston is not just the friction force in the polygon/slipper-contact. The transversal load of the cylinder $F_{x}$ is equal to that friction force $F_{\mu}$ only if the surface of the polygon ring is orthogonal to the piston axis, see eq. 1 . To detect the influence a tilting of the polygon may have on the transversal load, measurements with different displacements of the axis of the measured piston unit to the drive shaft axis were conducted. The test rig allows the variation of the displacement of the measured piston unit from $-2,5 \mathrm{~mm}$ up to $+2,5 \mathrm{~mm}$. The results of these measurements are shown in fig. 7 (rail pressure: $1800 \mathrm{bar}$; revolution: $200 \mathrm{rpm} / \mathrm{min}$ ).

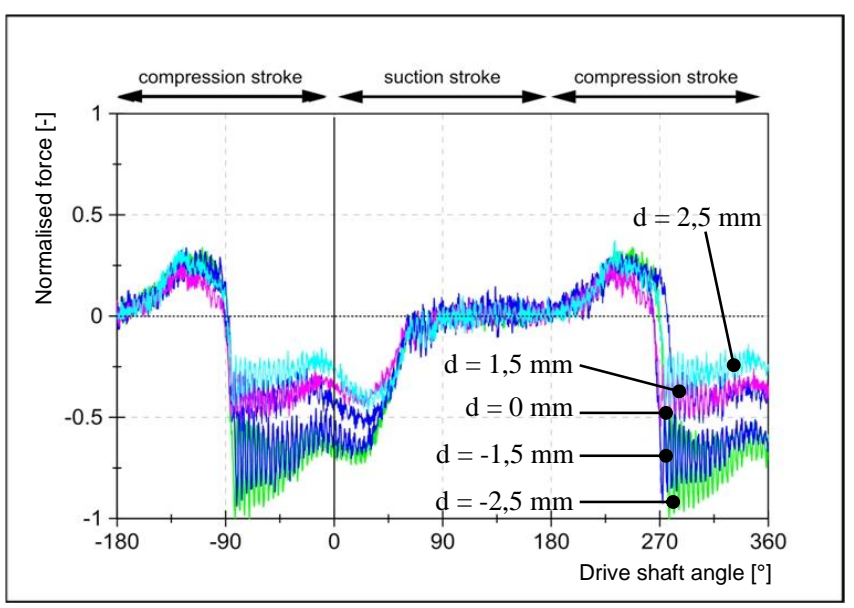

Figure 7: Measurement results for $F_{x}$ with different displacements

As it can be concluded from the results the displacement has a huge influence on the transversal load on the piston. The displacement of $-2,5 \mathrm{~mm}$ leads to the highest transversal load on the piston. The transversal load is reduced with every step the displacement takes towards $2,5 \mathrm{~mm}$. It can be assumed that the friction force $F_{x \mu}$ in the polygon/slippercontact is independent of the displacement and has approximately the same characteristic in all five measurements due to comparable tribological operating conditions of this contact. Hence, the variation in transversal load $F_{x}$ on the piston is caused by a different tilting characteristic of the polygon ring.

To draw conclusions from the measurement results concerning the most benificial displacement $d$ is not possible due to several reasons. Firstly, in the rig the displacement of only one piston unit is changed. The position of the other two piston units cannot be changed. Secondly, up to now only one operating point is measured, which is not a typical operating point of this kind of pump. It can be expected that the most beneficial displacement is a function of the operating conditions (revolution, pressure, temperature) as well as of the tribological properties of the fuel (lubricity and viscosity characteristic).

\section{Simulative Approach}

In the simulative approach, elastohydrodynamic models of the fuel-lubricated contacts were set up. In the following, a short introduction to the simulation tool will be provided. For more detailed information regarding the simulation tool the reader is referred to Knoll et al. [11, 12].

Solid bodies are incorporated in the simulation by FEMmodels. The local deformation and global rigid motion is determined by the integration of a special formulation of Newton's equation of motion, which combines large rigid body motions and small deformations of the elastic bodies, see eq. (2). The properties of the elasic bodies are incorporated in this equitation by the mass (M), damping (D) and stiffness (K) matrices, which are obtained from FEM-models. Centrifugal, gyroscopic and coriolis forces arising on the right hand side of eq. 2 besides external 
forces. The total acceleration vector $(\ddot{q}+\ddot{u})$ is separated into rigid body $(\ddot{q})$ and elastic accelerations $(\ddot{u})$.

$$
\mathbf{M} \cdot(\ddot{\mathbf{q}}+\ddot{\mathbf{u}})+\mathbf{D} \cdot \dot{\mathbf{u}}+\mathbf{K} \cdot \mathbf{u}=\mathbf{f}_{\mathrm{ext}}(t)+\mathbf{f}_{\mathrm{ce}}(t)+\mathbf{f}_{\mathrm{co}}(t)+\mathbf{f}_{\mathrm{gy}}(t)
$$

Prior to the elastohydrodynamic simulation, a reduction scheme is applied in order to achieve acceptable computation time by limiting the number of degrees of freedom (DOFs) of conventional finite element models. With the help of the reduction step, the modeling capabilities of the structure are reduced to reasonable deformation modes. It is important to choose relevant DOFs for the reduction step, because all solutions in the reduced system are weighted by superposition of these modes. In this reduction procedure, which is called mixed Guyan/modal reduction scheme, two different kinds of DOFs have to be chosen. The first group, the so-called static Ritz vectors model local deformations in stiff regions. These DOFs are used to cover the local deformations of for example bearing surfaces or surfaces were a load is applied. The second kind of DOFs are the so-called modal Ritz vectors. These DOFs represent the eigenvectors of the structure, which are obtained from a modal analysis. With the help of these DOFs global deformations can be represented by the reduced structures. The static and modal Ritz vectors represent the reduced DOFs and called static and modal DOFs, respectively. The reduction step is done once for each structure before the elastohydrodynamic simulation.

Besides standard coupling of different solid bodies by means of springs and dampers the solid bodies can be coupled via nonlinear hydrodynamic reaction forces which represent lubricating films. Those hydrodynamic forces are calculated on a separate 2 d-mesh by solving Reynolds equation for thin lubricating films, see eq. 3 . Microhydrodynamic effects are incorporated via flow factors according to Patir and Cheng [13], which are gained from measurements of real surface segments.

$$
\begin{aligned}
& \frac{\partial}{\partial x_{i}}\left(\Phi_{i j}^{p} \frac{\rho h^{3}}{12 \eta} \frac{\partial p}{\partial x_{j}}\right)=\quad ; i \neq 3 \\
& =\frac{v_{i 2}+v_{i 1}}{2} \frac{\partial(\rho h)}{\partial x_{i}}-\frac{v_{i 2}-v_{i 1}}{2} \sigma \sigma^{V} \frac{\partial\left(\rho \Phi_{i j}^{s}\right)}{\partial x_{j}}+\frac{\partial(\rho h)}{\partial t}
\end{aligned}
$$

Cavitation is considered by Reynolds boundary condition. The different fuels are characterised by their viscosity characteristics. Since high pressures and temperatures can occur in injection systems, the temperature and pressure dependency of the viscosity plays a major role. In order to determine the fuel viscosity characteristic, a viscometer for elevated pressure and temperature has been set up at IFAS [14]. Based on these viscosity measurements, models were parameterised and included in the simulation, see eq. 4 .

$$
\eta=\eta_{0} e^{\frac{\alpha p_{0}}{z}\left(\left(1+\frac{p}{p_{0}}\right)^{z}-1\right)}
$$

As soon as the hydrodynamic forces cannot bear the entire external forces on the lubrication film, solid body contact occurs. The contact pressure is determined with the help of the contact pressure curve. This curve is calculated based on measurements of real surface segments. If a critical gap height, which depends on the surface roughness of the parts sliding against each other, is reached during the dynamic analysis, solid body contact occurs. Friction forces are calculated according to eq. 5 .

$$
F_{\text {friction }}=\mu_{c} \int p_{c} d A_{c}+\int \eta \frac{\partial u}{\partial z} d A
$$

Up to now an energy equitation is not included in the simulation tool and hence local temperatures cannot be calculated by the simulation tool.

\section{Simulation Models}

\subsection{First Simulation Models}

In a first step simple simulation models for the polygon/slipper-contact as well as for the piston bushing contact were set up. In order to reduce simulation time, those two lubricating films were simulated in separate models. The simulated friction force in sliding direction (polygon/slipper simulation) is transferred to the piston in the piston/bushing simulation as transversal load. A more detailed description of the models can be taken from [15].

The viscosity characteristic of the fuels is incorporated according to eq. 4 . The parameters are set according to measurement results from a high pressure viscometer, which was set up at IFAS. The results of those measurements for several fuels at $\mathrm{T}=40^{\circ} \mathrm{C}$ are displayed in fig. 8. The intensive pressure dependency of some fuels becomes obvious.

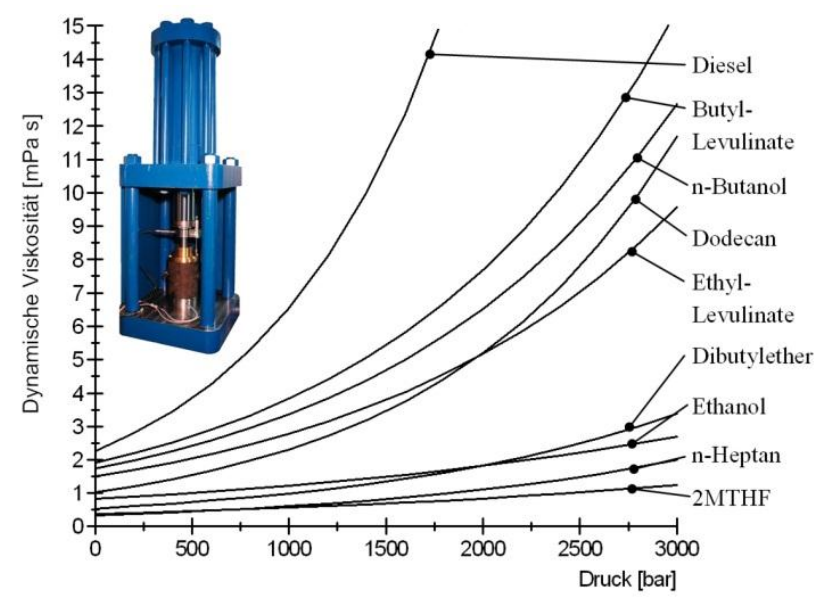

Figure 8: Pressure dependency of the viscosity at $40^{\circ} \mathrm{C}$ [16]

Fig. 9 shows the temperature dependency of some TMFB candidates at atmospheric pressure. In Common-RailSystems temperatures up to $120{ }^{\circ} \mathrm{C}$ and pressures up to 2000 bar have to be expected [17]. Hence, the temperature as well as the pressure dependency cannot be neglected in simulations. 


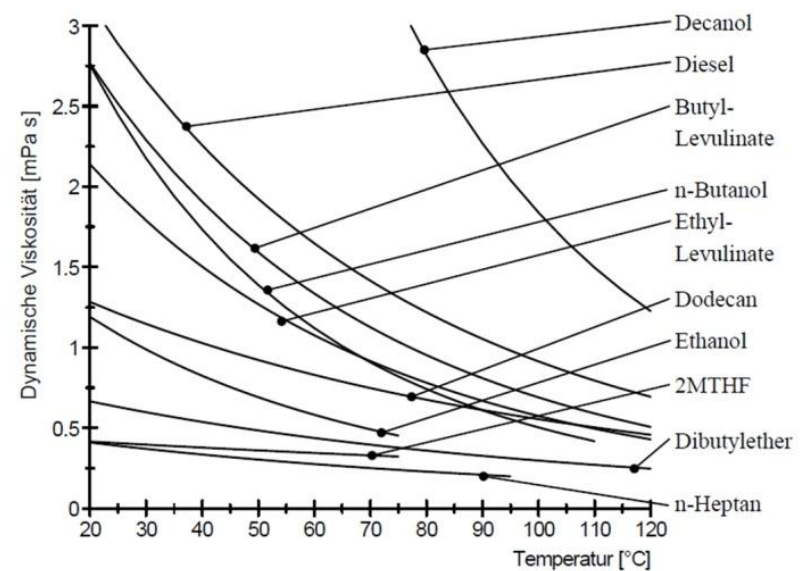

Figure 9: Temperature dependency of the viscosity at atmospheric pressure [16]

For the following simulations the promising fuel candidates dibutylether (DBE), 2-Methyltetrahydrofuran (2-MTHF) and butyl levulinate (BL) were chosen.

In fig. 10 simulation results for the bearing forces of the contact are pictured. At closer inspection of the results for the polygon/slipper-contact (left side of fig. 10) a huge influence of squeeze-effects can be identified, which reduces or even avoids solid body contact at the beginning of the compression stroke at $180^{\circ}$. Those squeeze-effects are viscosity-dependent and hence less distinctive for the fuel candidates like DBE, 2-MTHF and BL with a low viscosity. As a consequence, more solid body contact occurs if this contact is lubricated with those fuel candidates This leads to higher friction forces in the polygon/slipper-contact and consequently to a higher transversal load on the piston in the piston/bushing simulation. There, because of this higher load and due to the lower viscosity, more solid body contact occurs in this contact as well. All in all these results indicate that this kind of pump design is sensitive to fuel viscosity.

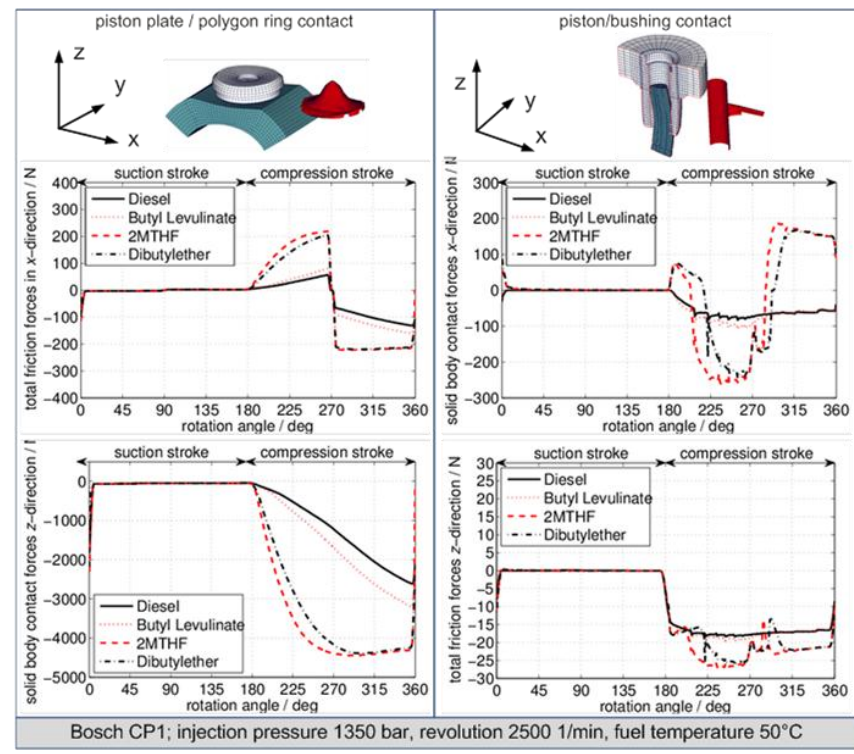

Figure 10: Test rig, layout (a) and hydraulic diagram (b)
The comparability of those models to a real pump is limited. For example the tilting of the polygon ring is not covered by the models and hence the transversal load on the piston is just the friction force $F_{x \mu}$ of the polygon/slipper-contact. Furthermore, an almost ideal shape of the pressure in the piston chamber was assumed. From $5^{\circ}$ to $175^{\circ}$ a constant suction pressure level of 3 bar was assumed and from $185^{\circ}$ to $355^{\circ}$ a constant injection pressure level. From $355^{\circ}$ to $5^{\circ}$ and from $175^{\circ}$ to $185^{\circ}$ the commutations in-between the pressure levels were assumed. As measurements at the test rig have shown, the pressure in the chamber raises slowly due to leakage, compressibility and elasticity.

\subsection{Improved Models}

In a next step those models were extended to achieve a better comparability of the measurement and the simulation. In the following these models - all in all three of them - are presented. In a first simulation the tilting $\varphi$ of the polygon is detected. This tilting $\varphi$ is an input for the second simulation. In this simulation the contact between polygon and slipper is modelled more accurately. The output of that simulation is the transversal load $F_{x}$ on the piston. The piston bushing contact is calculated in the last simulation. The reason for three separate models instead of one model for the whole pump is once again the required computation time.

\subsubsection{Tilting of the Polygon Ring}

As measurements indicated, the tilting $\varphi$ of the polygon ring has a huge influence on the transversal load $F_{x}$ on the piston, see fig. 3. To consider this in the simulation, an additional elastohydrodynamic simulation tool was set up, see fig. 11 . The piston pressure input, which is displayed in fig. 11 as well, was determined a priori in a separate hydraulic simulation with the simulation tool DSHplus. This model consists of eight rigid or non-rigid solid bodies:

- $\quad$ piston (three times); rigid (0 DOFs)

- $\quad$ slipper (three times); non-rigid (50 DOFs)

- polygon ring (one time); non-rigid (100 DOFs)

- $\quad$ eccentric shoulder (one time); non-rigid (50 DOFs)

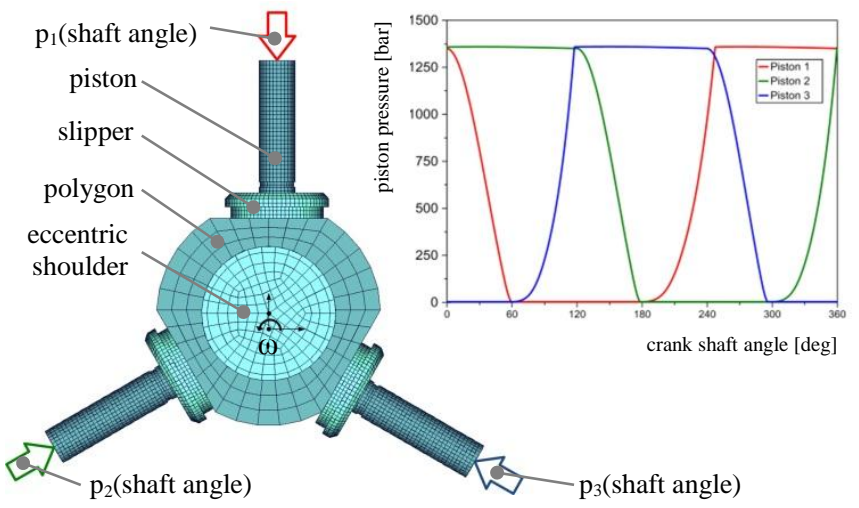

Figure 11: Simulation model for the tilting of the polygon

The eccentric shoulder is coupled with the polygon via a rotational journal bearing (140 nodes) and the three slippers 
are coupled to the polygon via axial journal bearings (71 nodes). All bearings are lubricated with fuel. The way the piston is coupled to the slippers has a high influence on the tilting of the polygon. In the pump, the piston is held down to the slipper by a small metal clip, see fig. 12 . This clip does not block a tilting up to a tilting angle of $4^{\circ}$ in both directions. As soon as piston and slipper axis are not concentric, not the whole bottom surface transfers the load from the piston to the slipper. On one side of the contact a gap arises and on the other side the load is transferred via solid body contact pressure of the contacting surfaces. In the simulation this characteristic could be modelled with the help of a lubricating film. But since the computation effort to solve the Reynolds equitation on this film and to determine the contact pressures on the bearing surfaces is huge, this option is not implemented in the simulation model. Instead another solution, which reduces computation time dramatically, is chosen. Each piston is coupled with its slipper via three compression springs, see fig. 12. With this kind of coupling the basic characteristic of the contact between piston and slipper in the pump can be modelled, assuming an adequate parameterisation of those three springs.
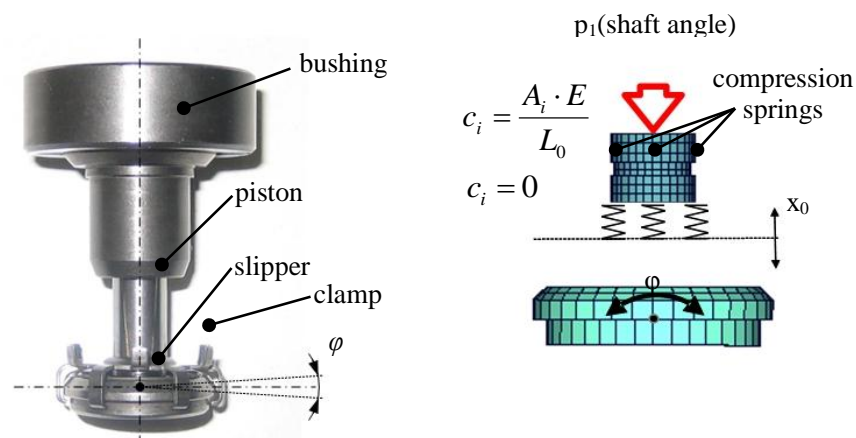

Figure 12: Coupling of piston and slipper

\subsubsection{Polygon/Slipper-Contact}

The second simulation is a more precise simulation of the polygon/slipper-contact, see fig. 13. In this simulation only one lubricating fuel film is covered and there are only three solid bodies:

- $\quad$ piston; non-rigid (0 DOFs)

- $\quad$ slipper; non-rigid (250 DOFs)

- $1 / 3$ polygon; non-rigid (300 DOFs)

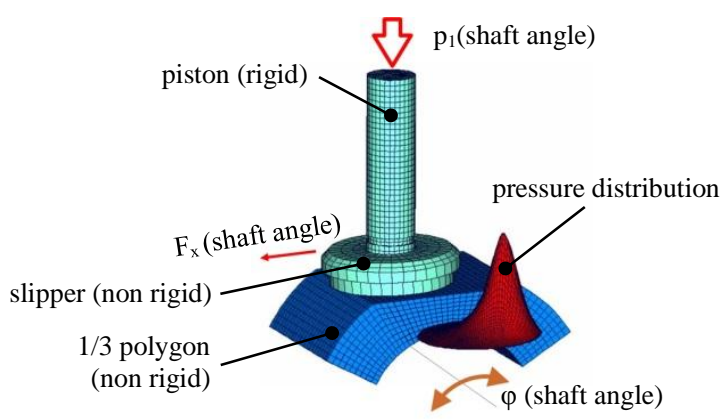

Figure 13: Simulation model for the polygon/slipper-contact
The polygon is tilted as a function of the shaft angle according to the results of the first simulation. In order to get more accurate results the number of DOFs of the slipper and polygon is increased in comparison to the first simulation. Furthermore, the 2d-mesh representing the lubricating film between slipper and polygon is defined more precisely (1871 nodes). The piston is modeled as a rigid body. The coupling between piston and slipper is implemented by three compression springs again. This simulation delivers as a result the transversal load $F_{x}$ on the piston as a function of the shaft angle.

\subsubsection{Piston/Bushing-Contact}

The third and last model is a more accurate model of the piston/bushing-contact, see fig. 14.

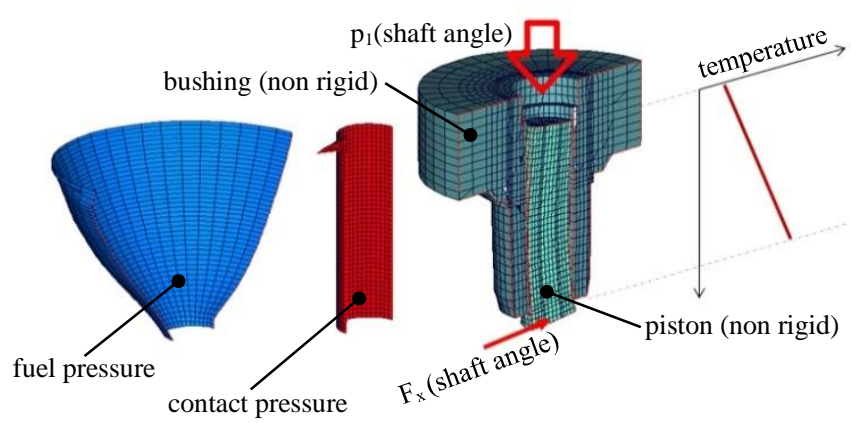

Figure 14: Simulation model for the piston/bushing-contact

The solid bodies, the piston and the bushing, are modeled as non-rigid bodies with 100 DOFs and 300 DOFs respectively. The lubricating film along the piston/bushingcontact is represented by a $2 \mathrm{~d}$-mesh with 1936 nodes. Along the gap in axial direction the pressure level is reduced by throttling effects. At the top end of the piston the pressure is on a high level during the compression stroke and at the lower end the pressure level is equal to the pressure level in the pump housing. The fuel is throttled from the piston chamber pressure level to the pressure level in the housing, as it can be seen in the fuel pressure distribution in fig. 13 . In real pumps this energy dissipation leads to a heating of the fuel along the gap. Since the energy equation is not implemented in the model, thermal effects are included in a simplified manner. As measurements in literature show [18], the temperature distribution along the bushing is approximately linear. This knowledge is used to define a temperature-dependent reference viscosity $\eta_{0}$ along the $\mathrm{z}$ direction of the lubricating gap.

\subsection{Simulation Results}

In the following some results of the improved models are presented. The simulated operating point is the same like in fig. 10 (rail pressure: 1350 bar; revolution: 2500 1/min, temperature: $50-100^{\circ} \mathrm{C}$ ). 


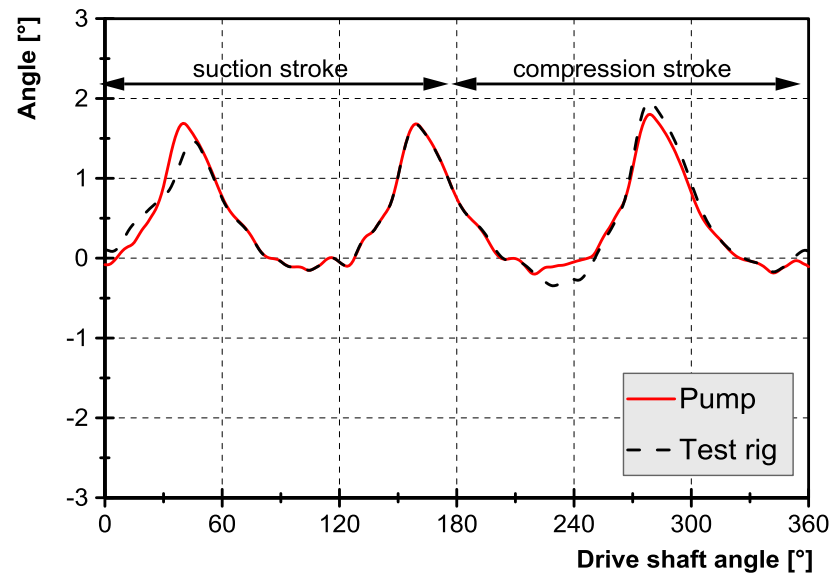

Figure 15: Results regarding the tilting of the polygon

In fig. 15 the simulated tilting of the polygon is plotted. A periodic characteristic is visible. Every $120^{\circ}$ a peak up to $1.8^{\circ}$ occurs due to the commutation. The dashed line represents the simulation results for the tilting of the polygon in the test rig. This tilting differs from the tilting in a standard pump due to the deviating pressure build-up in the measured piston unit (piston 1) in comparison to the other two piston units in that test rig. As explained before, the pressure build-up in the measured piston unit is slowed down by leakage at the compensation piston and by an increased dead volume.

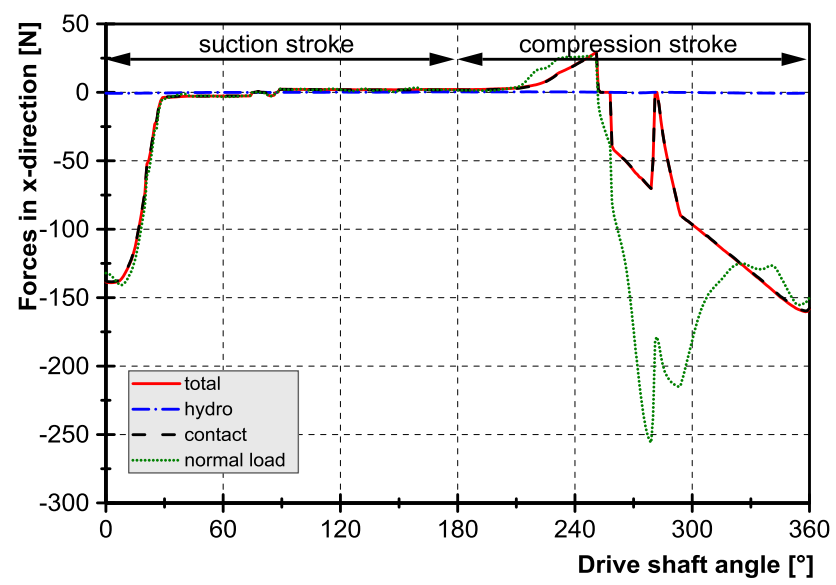

Figure 16: Results regarding friction forces of the polygon/slipper-contact and the transversal load on the piston

Figure 16 shows the friction forces in the polygon/slippercontact and the transversal load $F_{x}$ on the piston. Besides the total friction force $F_{\mu}$ its share resulting from solid body friction and its share due to hydrodynamic friction are plotted. The hydrodynamic share is neglectable so that almost all the friction in this contact is due to solid body friction. Because a tilting of the polygon occurs, the transversal load deviates from the total friction force. Only when the tilting angle is zero the transversal force $F_{x}$ is identical to the friction force $F_{\mu}$, e.g. at $325^{\circ}$.

Comparing the simulation results for the transversal load on the piston of the first simulation models plotteted in fig. 10 (upper left side) to the results of the improved models it is visible that the transversal load simulated with the improved models is oscillating due to tilting of the ring. This characteristic is not visible in the results of the first models in fig. 6. There the transversal load is steadily rising during the compression stroke. In the measurement results plotted in fig. 6 and 7 an oscillating characteristic similar to the results of the improved models is visible, too. Neverthless, a comparison of measurement and simulation is disputable at this point because of different operating points in the simulation and the measurement.

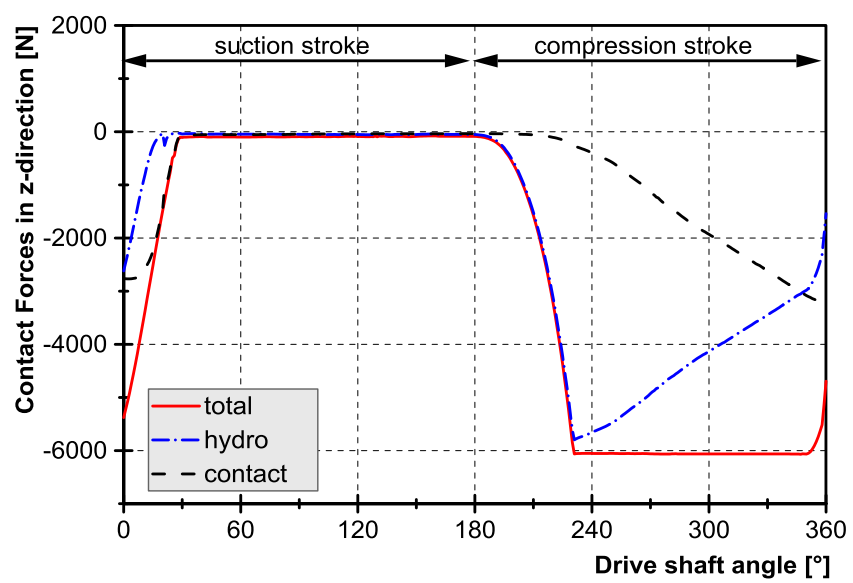

Figure 17: Results regarding contact forces of the polygon slipper-contact

In fig. 17 the contact forces in the polygon/slipper-contact are presented. Again distinctive squeeze-effects at the beginning of the compression stroke are visible. Solid body contact is avoided or reduced by these effects at the beginning and hence the friction force in $\mathrm{x}$-direction starts on a low level. Later on, this effect decreases and consequently more and more of the load is carried by solid body contact.

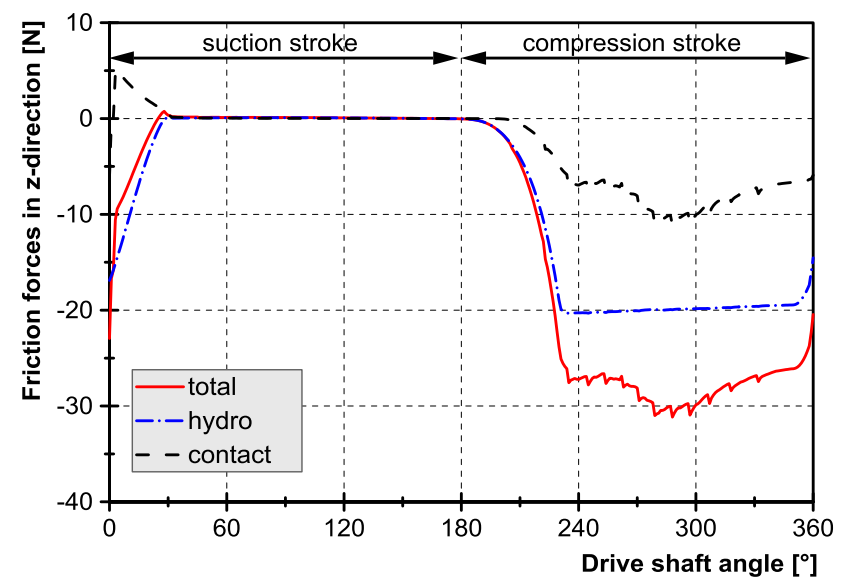

Figure 18: Results regarding friction forces of the slipper/polygon-contact

Figure 18 presents the friction forces in the piston/bushingcontact. Again, the total friction force is divided into its hydrodynamic friction share and its contact friction share. In contrast to the polygon/slipper-contact, the hydrodynamic 
friction share is not negligible. Because of the huge pressure difference during the compression stroke of 1350 bar an intensive poiseuille flow leads to a hydrodynamic friction force of roughly $20 \mathrm{~N}$. Because of the transversal load on the piston solid body contact occurs and hence a solid body friction force.

\section{Conclusion and Outlook}

In this paper an experimental and simulative approach for investigating the impact of new biofuels on the tribological contacts in common rail pumps was presented. Potential for further improvements on the experimental side and first results were discussed. These results are indicating a huge influence of the tilting $\varphi$ of the polygon on the transversal load $F_{x}$ on the piston. On the simulative side first simulation models and results for different fuels were presented. Those first models do not capture the tilting of the ring. In order to achieve a better compatibility with the measurements, the simulation models were improved and extended. The results for diesel show a better compatibility to the measurements, but a validation of the simulation by the measurement is not possible at this time, because there are several drawbacks mainly on the experimental side. To further increase comparability, improvements of the test rig will be done. This includes improvements of the pressure control in the rail, a better capturing of local temperatures and leakage measurements at the piston or at the compensation piston. After those modifications, testing of more typical operating points at higher speeds of more than $1000 \mathrm{rev} / \mathrm{min}$ will be possible as well as testing of different fuels.

\section{Acknowledgement}

This work was supported by the Deutsche Forschungsgemeinschaft (German Research Foundation) within the cluster of excellence 236 "Tailor-made Fuels from Biomass" [EXC 236].

\section{Nomenclature}

\begin{tabular}{lll}
\hline Designation & Denotation & Unit \\
\hline$A$ & Area & {$\left[\mathrm{m}^{2}\right]$} \\
$f_{c e}$ & Centrifugal force & {$[\mathrm{N}]$} \\
$x$ & Coordinate & {$[\mathrm{m}]$} \\
$f_{c o}$ & Coriolis force & {$[\mathrm{N}]$} \\
$D$ & Damping matrix & \\
$\rho$ & Density & {$\left[\mathrm{kg} / \mathrm{m}^{3}\right]$} \\
$d$ & Displacement & {$[\mathrm{m}]$} \\
$e$ & Eccentricity & {$[\mathrm{m}]$} \\
$E$ & E-module & {$\left[\mathrm{N} / \mathrm{m}^{2}\right]$} \\
$f_{\text {ext }}$ & External force & {$[\mathrm{N}]$} \\
$\Phi$ & Flow factor & {$[-]$} \\
$F_{i}$ & Force & {$[\mathrm{N}]$}
\end{tabular}

$\mu$

$h$

$f_{g y}$

$L$

$M$

$p$

$c$

$\boldsymbol{K}$

$T$

$\varphi$

$t$

$v$

$\eta$

\section{References}

[1] A Fatemi, K Mausch, H Murrenhoff, K Leonhard. Experimental investigation and theoretical prediction of the lubricity of biofuel components. In: Fluid power and motion control: (FPMC 2010). Basildon : Hadleys, 2010. - ISBN 978-0-86197-181-4, pp. 39-51

[2] K Mausch, A Fatemi, H Murrenhoff, K Leonhard. A COSMO-RS based QSPR model for the lubricity of biodiesel and petro-diesel components. In: Lubrication Science 23 (2011), Nr. 6, pp. 249-262. - ISSN 15576833

[3] K Reif. Moderne Diesel-Einspritzsysteme. Wiesbaden : Vieweg + Teubner Verlag / GWV Fachverlage GmbH, 2010. - ISBN 978-3834813121

[4] K-Th Renius. Untersuchungen zur Reibung zwischen Kolben und Zylinder bei SchrägscheibenAxialkolbenmaschinen. In: VDI Forschungsheft 561, VDI-Verlag, Düsseldorf, 1974

[5] O Koehler. Anlaufreibungsverluste eines Schrägscheiben-Axialkolben-Motors. In: Ölhydraulik und Pneumatik Nr. 31, Jahrgang 11, 1987

[6] S Donders. Kolbenmaschinen für HFA-Flüssigkeiten Verlustanteile einer Schrägscheibeneinheit. Verlag Mainz, Aachen, 1998

[7] A Kleist. Berechnung von Dicht- und Lagerfugen in hydrostatischen Maschinen. Shaker Verlag, Aachen, 2002

[8] R Lasaar. Eine Untersuchung zur mikro- und makrogeometrischen Gestaltung der Kolben/Zylinderbaugruppe von Schrägscheibenmaschinen. VDI Verlag, Düsseldorf, 2003 
[9] D Breuer. Reibung am Arbeitskolben von Schrägscheibenmaschinen im Langsamlauf. Shaker Verlag, Aachen, 2007

[10]S Drumm, S Heitizg, H Murrenhoff. Friction measurement of plunger bushing contact in fuel injection pumps. Proc. of Bath/ASME Symposium on Fluid Power \& Motion Control, ISBN: 978-0-86197187-9, S./Art.: 51-58

[11]G Knoll, R Schönen, K Wilhelm. Full Dynamic Analysis of Crank-shaft and Engine Block with Special Respect to Elastohydrodynamic Bearing Coupling. In: Proceedings of the ASME Internal Combustion Engine (ICE) Division Meeting Bd. 28, 1997, pp. 1-8

[12]R Schönen. Strukturdynamische Mehrkörpersimulation des Verbrennungsmotors mit elastohydrodynamischer Grundlagerkopplung. Kassel: Kassel Univ. Press, 2003 (Fortschrittsberichte Strukturanalyse und Tribologie, Teil 15). - ISBN 3-89958-507-0

[13]N Patir, H S Cheng. Application of Average Flow Model to Lubrication Between Rough Sliding Surfaces. In: Journal of Lubrication Technology 101 (1979), Nr. 2, pp. 220-229

[14]S Drumm, A Wohlers, A Fatemi, H Murrenhoff. Viscosity and bulk modulus measurements under high pressure conditions. In: Society of Tribologists and Lubrication Engineers annual meeting and exhibition 2010: Las Vegas, Nevada, USA, 16 - 20 May 2010. Red Hook, NY : Curran, 2010. - ISBN 978-1-61738-7272, pp. 413-416

[15]S Heitzig, S Drumm, L Leonhard, H Murrenhoff, J Lang, G Knoll. Simulative Analysis of the Tribological Contacts of Common Rail Injection Pumps Lubricated by Tailor-Made Biofuels. In: Tribologie und Schmierungstechnik

[16]S. M. Drumm. Entwicklung von Messmethoden hydraulischer Kraftstoffeigenschaften unter Hochdruck. Shaker Verlag, Aachen, 2012

[17] T. Illner,. Oszillierendes kippbewegliches Axialgleitlager bei Grenzreibung und Kraftstoffschmierung. Shaker Verlag, Aachen, 2010

[18] J Blume. Druck- und Temperatureinfluß auf Viskosität und Kompressibilität von flüssigen Schmierstoffen, RWTH Aachen, Diss., 1987 